\title{
'Informees' as Informers? An Approach to Effective Informing
}

\author{
Iwona Miliszewska and Anne Venables \\ Victoria University, Melbourne City, Australia
}

\author{
Iwona.Miliszewska@vu.edu.au
}

\begin{abstract}
An Intelligent Systems subject is offered in the final year of the Computer Science degree. The subject includes a diverse selection of topics in artificial intelligence and intelligent agents. The paper reflects on an innovative approach to the implementation of this subject. The development of the approach drew on educational research and the Informing Science paradigm. The aims of the approach included enga ging students in active learning, integrating theory with practice, and presenting the subject matter in an effective way. An innovative aspect of the approach was participatory teaching, i.e. students acting as guest lecturers and workshop presenters. The paper presents evaluation results indicating that the aims of the approach were achieved to a large extent.
\end{abstract}

Keywords: education, participatory teaching, active learning, experiential learning.

\section{Introduction}

Teaching is always a challenging task, and teaching computer science at university is no exception. One of the challenging aspects of teaching computer science is relating theory to practice. It may be quite straightforward in an introductory programming subject, as the subject focuses on a single programming language, and various programming concepts can be easily supported by suitable examples: an industry expert is not required to relate, for instance, the 'while' loop to the real world. However, the task is more complicated when teaching advanced subjects which include a diverse selection of topics on cutting edge technologies directly applicable to the real world. The Intelligent Systems subject is one example of an advanced subject with topics ranging from artificial intelligence, neural networks, through intelligent agents. How are they to be demonstrated, and by whom?

Another challenge is to give all students an equal chance of achieving best outcomes by catering for their individual preferred ways of learning. Some students learn better by observing, some by experimenting, and others, by reflecting. How are all these learning styles to be accommodated?

Keeping the students' interest up is also a tall order as, after all, computer science does not seem particularly entertaining; yet, in learning, fun is an important addition to content. Just as demanding is the creation of a learning environment where students participate, moreover enjoy participating, in the teaching process. How should such an environment be constructed? How should students be involved? How

Material published as part of these proceedings, either on-line or in print, is copyrighted by Informing Science. Permission to make digital or paper copy of part or all of these works for personal or classroom use is granted without fee provided that the copies are not made or distributed for profit or commercial advantage AND that copies 1) bear this notice in full and 2) give the full citation on the first page. It is permissible to abstract these works so long as credit is given. To copy in all other cases or to republish or to post on a server or to redistribute to lists requires specific permission from the publisher at Publisher@Informingscience.org should elements of fun and adventure be incorporated?

This paper presents an approach, which proposes answers to the above challenges. The approach aims at improving teaching, optimizing students' ability to benefit from teaching, and enhancing academic quality. It concentrates on learning and teaching situations while maintaining focus on the quality of learning. The paper identifies the prin- 
'Informees' as Informers?

ciples underpinning the approach, and refers it to related research findings. It reflects on the application of this approach to an advanced computer science subject - Intelligent Systems.

\section{The Subject}

Intelligent Systems is a final year subject of a Computer Science degree. Its content encompasses a broad range of diverse areas from artificial intelligence to intelligent agents; students are introduced to problem solving strategies and heuristics currently applied in these sciences. In addition, real-world applications of theses approaches are presented, and related research issues discussed. Subject content includes the issues of intelligence in general, the difference between human and machine intelligences, the concept of an intelligent system, and methods for knowledge representation.

Students enrolling in the Intelligent Systems subject must have completed two programming subjects. As part of the Computer Science degree, Intelligent Systems mostly attracts students majoring in computer science, however it also appeals to engineering students as an elective study. As a consequence of the liberal prerequisite requirements and broad subject appeal, the subject includes a heterogeneous student group representing a broad range of background skills and differing ways of learning.

The subject is presented over one semester (thirteen weeks) through two one-hour lectures and one onehour supporting practical/tutorial session a week. Ideally all the subject content should be covered during that time, however given the delivery framework and time limit, it is impossible to cover all the different fields of study well. A suitable subset needs to be chosen, balancing the diversity of subject matter with students' backgrounds, skill levels and ways of learning. The availability of suitably equipped laboratories and software is yet another limiting factor. In addition, the expertise and experience of the presenter need to be taken into account. In a subject exploring several cutting edge technologies, even the most capable lecturer could not be expected to have mastered them all.

\section{The Approach}

To innovate is to re-examine our ways of seeing and doing things, ..., to be actively curious and reflectively active, to reinvent constantly our visions and approaches. To innovate is to be alert, ..., to create and to enjoy creating, and, by doing so, to share innovative experiences with others. (Belanger \& Jung, 1997).

Examination of previous, very 'traditional', offerings of the Intelligent Systems subject led to a search for 'new', and 'better', ways of teaching it. The development of a new teaching approach was not just about the activities of the teacher; rather it was a plan for students' learning. The plan had to include the presentations that the teacher would make, the exercises and activities in which the students would participate, materials that would be supplied to the students, and ways in which students' understanding and capabilities would be assessed.

\section{Client/Server}

The core idea of the approach came from two sources: Informing Science and computer networks architectures. Cohen (1999) defined the term Informing Science as a variety of disciplines that 'share the common goal of providing a client with information in a form, format, and schedule' that 'optimizes the client's ability to benefit from that information'. Education could, therefore, be regarded as an informing discipline and students as clients to be informed. This conceptualization of education brought a desired focus on students and the 'learner-centered learning' advocated by Knowles et al. (2001), but still left clients - students - on the receiving side of information and the teacher in the role of provider - server. The term client/server, however, is also present in a different environment: that of computer networks. A client/server network architecture is one where a number of computers are connected through a network, 
whereby one computer in the network acts as a server, or provider of information, and all other computers only request and receive information: they are the clients. Education too could be regarded as an interconnected environment with the teacher acting as a server and students as clients. Interestingly, the distinct roles of clients and servers in computer networks have undergone a significant transformation in recent years in that clients also provide information and servers request and receive it. This development inspired a notion of applying similar transformation to education. Consequently, in the approach students could play dual roles of both clients - learners ('informees') - as well as servers - teachers (informers). Likewise, the teacher could be both a teacher as well as a learner. Research promotes reciprocal roles of teachers and learners, and stresses their interdependence (McLoughlin \& Oliver, 1999). It also advocates a shared responsibility for creating and exploring knowledge (Scardamalia \& Bereiter, 1991; 1994). An inquiry was conducted to assess the feasibility of the client/server facet of the approach prior to its implementation; a number of students, capable and willing to participate, were found.

\section{Optimized Learning}

Optimization of student's ability to learn was another part of the approach. One important factor affecting this ability is the student's preferred learning style. Feldman \& Hofinger (1997) presented an interesting discussion on how the use of different learning styles helps students better retain knowledge. The four styles are concrete experience, abstract conceptualization, reflective observation and active experimentation or, in other terms, feeling, thinking, watching and doing. A person may prefer one learning style to the other; however, learning will be greatly enhanced if a person is actively involved in all of them. It is accepted that students do have preferred learning styles, and that learning can be significantly increased if teaching strategies are matched to them (Dunn, 1984). However, it is also recognized, that new learning styles can be developed, and existing ones improved to increase the variety of opportunities from which students might subsequently learn (Bargar \& Hoover, 1984; Hyman \& Rosoff, 1984; Joyce, 1984). It was decided that, to benefit all students equally, the approach would include activities and assessment designed to accommodate a variety of learning styles. For instance, an assignment involving the development of an expert system would favor the 'thinkers' and 'doers', a mid-semester test examining the understanding of acquired knowledge would suit 'watchers', and writing a report on workshop demonstrations would give preference to 'feelers' and 'thinkers'.

\section{Practiced Theory}

Another aspect of the approach was the emphasis on integrating theory with practice. This facet is associated with the experiential way of learning, described by Kolb (1984) and Kolb \& Fry (1975) as a cyclical process passing through four stages: experiencing, reflecting, concluding and testing. The experiential method was specifically developed to link theory to practice in a waythat would promote 'deep' rather than 'surface' learning. It was agreed that in the approach introduction of theoretical concepts would be supported by either practical laboratory tasks, or presentations of real- life applications, or workshops including the use of commercial software, or demonstrations fully developed products, e.g. robots.

\section{Project Work}

A further feature of the approach was the development of problem solving skills and a capacity for independent work, referred to in literature as a project work. The project work can vary in complexity and scope from a project exercise, through a project component and project orientation (Morgan, 1984). For the Intelligent Systems subject the micro scale of the project was chosen as the most appropriate, i.e. the project exercise. In this exercise, students would apply the knowledge and skills that they have acquired to problem in a subject area already familiar to them. 
'Informees' as Informers?

\section{Motivation}

Last but not least, the approach included fun and discovery as factors stimulating students' curiosity and continuing engagement. According to Knowles et al. (2001), students learn only if they are motivated and ready to learn. The pursuit of adventurous teaching and active learning has also been advocated by McLoughlin \& Oliver (1999). It was agreed that this philosophy would be echoed throughout the approach but, in particular, the combination of content and entertainment would be reflected in specially designed puzzle- and quiz-like cha llenges.

\section{The Implementation}

Previous offerings of Intelligent Systems covered only two or three areas of study. On this occasion, a deliberate attempt has been made to widen the breadth of the subject and increase students' exposure to the diversity of topics while, at the same time, illustrating theory with practical applications and exposing students to new technologies. The subject topics were divided between the lecture presentations, approximately two weeks of class time to the each of the main areas. The lectures were supported by practical/tutorial sessions structured in a way that would give students the opportunity to experience, test and reflect upon practical applications of theory presented in the lectures. For example, after the topic fuzzy logic had been covered in the lectures, students simulated the operation of fuzzy logic based systems; one was a shower with fuzzy inputs of hot and cold water and valve pressures; another, a commercial washing machine with fuzzy control of washing cycles.

\section{'Informees' as Informers}

It has not always been possible to appoint a lecturer-in-charge of Intelligent Systems who possesses expertise in each field of artificial intelligence. Such circumstances presented an opportunity for student 'experts' to assume the roles of lecturers, presenters and demonstrators; students showcased their research, demonstrated applications of commercial software, and presented experimental solutions to pertinent problems. Some of the events are described in the following sections.

\section{Presentations}

Robocup is an international competition for students of all ages who compete in a game of robot soccer with their custom designed and built robots. One of the competitors, a student from another university participating in the 2002 tournament, gave a presentation to the Intelligent Systems class. Armed with two competitive robots and video footage of the various stages of the competition, the guest lecturer related some of the difficulties associated with mounting a successful Robocup challenge, and demo nstrated solutions to the generic problems of computer motion, vision, and interactive co-operation between computers. The demonstration was interwoven with hands-on trials and punctuated with ane cdotes. It stimulated interest and discussion in Robocup competition, robots and intelligent systems.

A research student gave a lecture on neural networks; he shared details of his project on artificial ne ural networks used in solving a real- world problem for the Australian Navy. The student described his research, which involved devising and then training a neural network with known directions of sea waves known as wave heading readings. Once trained, the neural network was then suitable for use at sea without the original need for land stations to compute wave-heading directions that could strike a vessel.

\section{Demonstrations}

'Expert' students, with an engineering background, designed and conducted interactive demonstrations on neural networks for their fellow Intelligent System students. Four different problems were chosen, and solutions to those proble ms presented using a commercial neural network software package. In one 
case, the application of a neural network was a deliberate counter-example, as the neural network did not provide a suitable solution and its use was not appropriate. The other three cases were class ical problems that could be solved using a neural network. All four demonstrations stimulated experimentation and discussion that reinforced learned theory presented in lectures. An assessment exercise was then set that required participating students to submit a written report answering several key questions about the four given problems. These questions asked students for comments on what they had learned from the peerled demonstrations.

\section{Assessment}

The continuous assessment of the subject comprised three parts a project, a mid-semester test, and a report on a tutorial demonstration. While the mid-semester test examined the understanding of the topics covered in the first part of the subject, and the tutorial report tested students' ability to reflect on the relationship between theory and practice, the project was a creative task.

The project involved the design and implementation of a rule-based expert system. In a lead up to the project, students were expected to complete a set of standard tutorial exercises to learn the basics of an expert shell known as JESS, and then apply the acquired skills to solve a real-world problem. The project specification detailed grading for a range of solutions. A standard solution, worth $70 \%$ of the total mark, involved the creation of a typical expert system that adequately solved the problem. Several possible extensions to the solution were suggested, allowing the more motivated students to incorporate these or other possible extensions to enhance the functionality of their expert system. Additional marks were awarded for these extensions, their number dependent upon the degree of difficulty and innovation involved.

\section{The Evaluation}

The effectiveness of the core premises of the approach was evaluated by a questionnaire completed by sixty-six out of one hundred students in October 2002, soon after the last guest lecture was conducted. A 5-point Likert scale was used, where 5 indicated strongly agree and 1 indicated strongly disagree. The results are reported in Table 1 as percentages on the Likert scale. 


\begin{tabular}{|c|c|c|c|c|c|}
\hline Robocup presentation & 5 & 4 & 3 & 2 & 1 \\
\hline $\begin{array}{l}\text { It was good that the presentation was } \\
\text { given by a student. }\end{array}$ & $17 \%$ & $68 \%$ & $9 \%$ & $3 \%$ & $3 \%$ \\
\hline $\begin{array}{l}\text { It was good to see solutions to AI prob- } \\
\text { lems presented in an entertaining way. }\end{array}$ & $31 \%$ & $63 \%$ & $6 \%$ & & \\
\hline $\begin{array}{l}\text { It was an interesting and memorable ex- } \\
\text { perience. }\end{array}$ & $15 \%$ & $66 \%$ & $19 \%$ & & \\
\hline $\begin{array}{l}\text { Work on a project like ROBOCUP should } \\
\text { be part of the Intelligent System subject. }\end{array}$ & $20 \%$ & $55 \%$ & $20 \%$ & $3 \%$ & $2 \%$ \\
\hline Wave-Heading lecture & 5 & 4 & 3 & 2 & 1 \\
\hline $\begin{array}{l}\text { It was good that the guest lecture was } \\
\text { given by a student }\end{array}$ & $17 \%$ & $58 \%$ & $21 \%$ & $4 \%$ & \\
\hline $\begin{array}{l}\text { It was good to see a real-world applica- } \\
\text { tion of neural networks. }\end{array}$ & $28 \%$ & $59 \%$ & $12 \%$ & $1 \%$ & \\
\hline $\begin{array}{l}\text { It would be a good idea to make such lec- } \\
\text { tures part of the subject. }\end{array}$ & $16 \%$ & $53 \%$ & $27 \%$ & $3 \%$ & $1 \%$ \\
\hline Neural Network demo nstrations & 5 & 4 & 3 & 2 & 1 \\
\hline $\begin{array}{l}\text { It was good that the demonstrations were } \\
\text { given by st udents. }\end{array}$ & $24 \%$ & $55 \%$ & $16 \%$ & $5 \%$ & \\
\hline $\begin{array}{l}\text { The subject material was reinforced in a } \\
\text { clear and practical way. }\end{array}$ & $23 \%$ & $51 \%$ & $18 \%$ & $8 \%$ & \\
\hline $\begin{array}{l}\text { It was interesting to see suitable and un- } \\
\text { suitab le applications of neural networks. }\end{array}$ & $20 \%$ & $67 \%$ & $11 \%$ & $2 \%$ & \\
\hline $\begin{array}{l}\text { It was good that commercial software was } \\
\text { used in the demonstrations. }\end{array}$ & $18 \%$ & $61 \%$ & $21 \%$ & & \\
\hline $\begin{array}{l}\text { It was a memorable and interesting ex- } \\
\text { perience. }\end{array}$ & $15 \%$ & $53 \%$ & $28 \%$ & $4 \%$ & \\
\hline $\begin{array}{l}\text { It would be a good make such demonstra- } \\
\text { tions part of the subject. }\end{array}$ & $30 \%$ & $54 \%$ & $13 \%$ & $3 \%$ & \\
\hline
\end{tabular}

Table 1: Students' evaluation of guest lectures.

The results of the survey indicated that the client/server approach was warmly received by the students, as more than three quarters of the respondents approved, or strongly approved, of such an approach. Integrating theory with practice was viewed as very important, with over $80 \%$ of respondents approving demonstrations of real-world applications, and the use of commercial software. An overwhelming ma- 
jority of students supported the idea of making the client/server approach a permanent feature of the subject.

The effectiveness of the approach was further evaluated by continuous assessment. The project, involving the development of an expert system, challenged the students to look beyond the textbook and lecture material. Ninety-six of the one hundred and one students completed the project. All students passed, and there were a large number of outstanding efforts. A report on the neural networks demonstrations, which was also a part of continuous assessment, was submitted by ninety students. All students who submitted the report passed, with many outstanding results. Ninety-five out of ninety-nine students passed the final examination.

Overall subject evaluation was conducted at the end of the semester; sixty-two out of one hundred students completed the evaluation. Over $70 \%$ of respondents agreed that subject's objectives were clear, and that the subject was well taught; $60 \%$ agreed that the subject was intellectually stimulating and enjoyable. The practical work sessions were rated even higher, with almost $90 \%$ of students regarding them very useful in understanding the subject material, and nearly $70 \%$ agreeing that the sessions were well structured and easy to follow.

\section{Conclusions}

This paper described how an innovative approach to teaching an advanced Computer Science subject was developed and implemented. In developing the approach, much effort was expended on the form and structure of the teaching; attention was paid not only to what was to be taught, but also how it was to be taught. In the process, the teachers became themselves researchers and reflexive actors in their own educational practice. An evaluation of this approach was carried out through a student survey.

The survey results together with subject feedback have led to the following conclusions: employing a variety of teaching styles enhanced the learning performance of the students; swapping of roles enabled students to carry out independent investigation and critical evaluation of the problem at hand before formally presenting it to their peers; student participation, a key factor of the approach, played a crucial role as it enabled students to be involved in the development, presentation and the application of the relevant topics.

Effectiveness of teaching is a function of both student motivation and the content of the presented material: the teaching style and presentation are often as important as what is taught. In contrast to more traditional lecture styles, the presented approach encouraged students' participation in the teaching process, and employed a variety of presentation techniques. It also promoted concept demonstration through examples illustrating practical application of the underlying theory.

An important aspect of the approach was that the teacher was not the only source of knowledge. There was an implicit understanding that the teacher did not have all the answers, and that teaching and learning were a shared responsibility, the teacher being open to learning. In fact, some of the students, on occasion, assumed the roles of teachers. As a result, a more horizontal process of interaction developed between the teacher and the students. It was no longer a practice that depended primarily on the teacher.

As the initial survey demonstrated, the challenges and the opportunities presented by this innovative approach were not only welcomed and appreciated by the students, but also contributed to positive educ ational outcomes. The development of the approach is an ongoing research project and a number of important issues still need to be further investigated for example, determining methods to measure the effectiveness of the approach objectively, and improving the rate of participatory teaching. 


\section{'Informees' as Informers?}

There is not one right way to teach, just as there is not one right way to learn. There are certain principles for good teaching and good learning, but the practice of teaching and learning needs to be continually invented. This paper presented a step in the quest for continuous discovery.

\section{References}

Bargar, R.R. \& Hoover, R.L. (1984). Psychological type and the matching of cognitive styles. Theory into Practice, 1, $56-63$.

Belanger, P. \& Jung, I. (1997). Preface. In Mauch, W. \& Papen, U. (Eds.). Making a difference: innovations in adult education (p.9). Frankfurt am Mein, Germany: Peter Lang GmbH.

Cohen, E. (1999). Reconcepualizing information systems as a field of the transdiscipline informing science: from ugly duckling to swan. Journal of Computing and Information Technology. 7(3), 213 -219. Retrieved December 2001, from http://www.is2002.com/WhatIS.htm

Feldman, L.J. \& Hofinger R.J. (1997). Active Participation by Sophomore Students in the Design of Experiments, ASEE/IEEE Frontiers in Education Conference, pp.1526-1527.

Hyman, R. \& Rosoff, B. (1984). Matching learning and teaching styles: the jug and what's in it. Theory into Practice, 1, 3543.

Joyce, B.R. (1984). Dynamic disequilibrium: the intelligence of growth. Theory into Practice, 1, $26-34$.

Knowles, M., Holton, E. \& Swanson, R. (2001). The Adult Learner: The Definitive Classic in Adult Education and Human Resource Development. $5^{\text {th }}$ Edition. Woburn, MA: Butterworth-Heinemann.

Kolb, D.A. (1984). Experiential Learning: Experience as the Source of Learning and Development. Englewood Cliffs, NJ: Prentice Hall.

Kolb, D.A. \& Fry, R. (1975). Towards an applied theory of experiential learning. In Cooper, C.L. (Ed.) Theories of Group Process. Chichester: John Wiley.

McLoughlin, C. \& Oliver, R. (1999). Pedagogic roles and dynamics in telematics environments. In Selinger, M., \& Pearson, J. (Eds.) Telematics in Education: Trends and Issues (pp.32-50). Oxford: Pergamon.

Morgan, A. (1984). Project-based learning. In Henderson, E., \& Nathenson, M. (Eds.) Independent Learning in Higher Education. Englewood Cliffs, NJ: Educational Technology Publications.

Scardamalia, M., \& Bereiter, C. (1991). Higher levels of agency for children in knowledge building: A challenge for the d esign of new knowledge media. Journal of Learning Sciences, 1(1), 37-68.

Scardamalia, M., \& Bereiter, C. (1994). Computer support for knowledge building communities. Journal of Learning Sciences, 3(3), 265-283.

\section{Biography}

Iwona Miliszewska is a senior lecturer in Computer Science at Victoria University. She has participated in research projects involving distance education, effective teaching methods, lifelong learning and women in computer science, and has published in these areas.

Anne Venables is a lecturer in Computer Science at Victoria University. She has research and teaching interests in artificial intelligence and intelligence systems. As a former secondary Science and Mathematics teacher who has migrated into tertiary education, Anne is also interested in innovations in educ ation and has previously published in this field 